\title{
HIMPUNAN KOMPAK PADA RUANG METRIK
}

Oleh :

\section{Cece Kustiawan}

Jurusan Pendidikan Matematika FPMIPA

Universitas Pendidikan Indonesia

cecekustiawan@yahoo.com

\begin{abstract}
Makalah ini menyajikan definisi dan teorema-teorema himpunan kompak yang bertujuan untuk menentukan kekompakan suatu himpunan pada ruang metrik. Misalkan E adalah suatu himpunan yang tidak kosong pada ruang metrik (X,d). Akan ditentukan apakah E merupakan himpunan kompak atau bukan, yaitu dengan menggunakan definisi kompak atau dengan menggunakan teorema-teorema mengenai himpunan kompak.

Kata Kunci : Ruang Metrik, Persekitaran, Titik Limit, Interval Bersarang, Selimut Terbuka, Himpunan Terbuka, Himpunan Tertutup, dan Himpunan Terbatas.
\end{abstract}

This paper presents the definitions and theorems of compact set which aimed to determine the compactness of a set in a metric space. Suppose $\mathrm{E}$ is a non-empty set in a metric space $(\mathrm{X}, \mathrm{d})$. Be determined whether $\mathrm{E}$ is compact set or not, by using the definition of a compact set or use theorems on compact sets.

Keywords : Metric spaces, Neighborhood, Limit point, Nested interval, Open covering, Open set, Closed set, and Boundary set.

\section{Pendahuluan}

Untuk menentukan kekompakan suatu himpunan terlebih dahulu akan dibicarakan mengenai definisi ruang metrik, definisi selimut terbuka (open cover) untuk suatu himpunan, definisi himpunan kompak dan teorema-teorema pada himpunan kompak, antara lain; Teorema Heine-Borel, Teorema Bolzano-Weierstrass dan teorema-teorema yang lainnya yang berhubungan dengan himpunan kompak.

\section{Definisi 1}

Misalkan $\mathrm{X}$ himpunan yang tidak kosong. Fungsi $\mathrm{d}: \mathrm{X} \mathrm{x} \mathrm{X} \rightarrow \mathrm{R}$ disebut fungsi metrik (fungsi jarak) jika untuk setiap $p, q \in X$ berlaku :

(i) $\mathrm{d}(\mathrm{p}, \mathrm{q}) \geq 0$

$$
d(p, q)=0 \Leftrightarrow p=q
$$

(ii) $\mathrm{d}(\mathrm{p}, \mathrm{q})=\mathrm{d}(\mathrm{q}, \mathrm{p})$

(iii) $\mathrm{d}(\mathrm{p}, \mathrm{q}) \leq \mathrm{d}(\mathrm{p}, \mathrm{r})+\mathrm{d}(\mathrm{r}, \mathrm{q}), \forall \mathrm{r} \in \mathrm{X}$. 
Himpunan $\mathrm{X}$ dengan fungsi metrik d disebut ruang metrik dan ditulis dengan notasi $(\mathrm{X}, \mathrm{d})$.

\section{Contoh}

Himpunan $\mathrm{R}$ dengan metrik biasa $\mathrm{d}(\mathrm{x}, \mathrm{y})=|\mathrm{x}-\mathrm{y}|, \forall \mathrm{x}, \mathrm{y} \in \mathrm{R}$ merupakan ruang metrik, sebab memenuhi ketiga sifat metrik pada Definisi 1.

\section{Definisi 2}

Selimut terbuka himpunan $\mathrm{E}$ pada ruang metrik $(\mathrm{X}, \mathrm{d})$ adalah keluarga himpunan terbuka $\left\{\mathrm{G}_{\alpha}\right\}$ di $\mathrm{X}$ sehingga $\mathrm{E} \subset \bigcup_{\alpha} \mathrm{G}_{\alpha}$.

\section{Contoh}

(a) $(X, d)=(R, d)$ ruang metrik biasa, $E=(-1,1),\left\{G_{n}\right\}_{n \in N}=\left\{\left(-\frac{1}{n}, \frac{1}{n}\right)\right\}_{n \in N}$.

$\left\{\mathrm{G}_{\mathrm{n}}\right\}_{\mathrm{n} \in \mathrm{N}}$ adalah selimut terbuka untuk $\mathrm{E}$ sebab $\mathrm{E} \subset \bigcup_{\mathrm{n}=1}^{\infty} \mathrm{G}_{\mathrm{n}}=(-1,1)$.

(b) $(X, d)=(R, d)$ ruang metrik biasa, $F=(0,1),\left\{G_{n}\right\}_{n \in N}=\left\{\left(\frac{1}{n+2}, \frac{1}{n}\right)\right\}_{n \in N}$.

$\left\{\mathrm{G}_{\mathrm{n}}\right\}_{\mathrm{n} \in \mathrm{N}}$ adalah selimut terbuka untuk $\mathrm{F}$ sebab $\mathrm{F} \subset \bigcup_{\mathrm{n}=1}^{\infty} \mathrm{G}_{\mathrm{n}}=(0,1)$.

\section{Definisi 3}

Himpunan $\mathrm{K}$ dalam ruang metrik (X,d) dikatakan kompak jika setiap selimut terbuka untuk K memuat selimut bagian berhingganya untuk K.

Jadi himpunan $\mathrm{T}$ dalam ruang metrik $(\mathrm{X}, \mathrm{d})$ dikatakan tidak kompak jika ada selimut terbuka untuk $\mathrm{T}$ yang tidak memuat selimut bagian berhingganya untuk $\mathrm{T}$.

\section{Contoh}

(a) $(X, d)=(R, d)$ ruang metrik biasa, himpunan $F=(0,1)$ tidak kompak, sebab ada selimut terbuka untuk $\mathrm{F}$ yang tidak memuat selimut bagian berhingganya, yaitu $\left\{\mathrm{G}_{\mathrm{n}}\right\}_{\mathrm{n} \in \mathrm{N}}=\left\{\left(\frac{1}{\mathrm{n}+2}, \frac{1}{\mathrm{n}}\right)\right\}_{\mathrm{n} \in \mathrm{N}}$ merupakan selimut terbuka untuk $\mathrm{F}$ tetapi $\bigcup_{n=1}^{\mathrm{k}} \mathrm{G}_{\mathrm{n}}=\left(\frac{1}{\mathrm{k}+2}, 1\right), \mathrm{k} \in \mathrm{N}$ dan $\mathrm{F} \not \subset \bigcup_{\mathrm{n}=1}^{\mathrm{k}} \mathrm{G}_{\mathrm{n}}$.

(b) Sedangkan $\mathrm{H}=[0,1]$ dengan metrik biasa merupakan himpunan kompak sebab setiap selimut terbuka untuk $\mathrm{H}$ memuat selimut bagian berhingganya untuk $\mathrm{H}$. 
Untuk lebih jelasnya silahkan ambil beberapa contoh selimut terbuka untuk $\mathrm{H}$, tetapi itu bukan merupakan bukti.

\section{Teorema 4}

Jika K himpunan kompak dalam ruang metrik $(\mathrm{X}, \mathrm{d})$ maka $\mathrm{K}$ tertutup.

Bukti:

Diambil $\mathrm{p} \in \mathrm{K}^{\mathrm{c}}$ sebarang, kemudian untuk setiap $\mathrm{q} \in \mathrm{K}$ dibuat persekitaran $\mathrm{V}_{\mathrm{r}}(\mathrm{p})$ dan $\mathrm{W}_{\mathrm{r}}(\mathrm{q})$ dengan jari-jari $\mathrm{r}=\frac{1}{2} \mathrm{~d}(\mathrm{p}, \mathrm{q})$ maka $\mathrm{V}_{\mathrm{r}}(\mathrm{p}) \cap \mathrm{W}_{\mathrm{r}}(\mathrm{q})=\phi$. Jadi $\left\{\mathrm{W}_{\mathrm{r}}(\mathrm{q})\right\}_{\mathrm{q} \in \mathrm{K}}$ merupakan selimut terbuka untuk K. Karena K kompak maka ada $\mathrm{q}_{1}, \mathrm{q}_{2}, \cdots, \mathrm{q}_{\mathrm{n}}$ sehingga $\mathrm{K} \subset \bigcup_{\mathrm{i}=1}^{\mathrm{n}} \mathrm{W}_{\mathrm{ri}}\left(\mathrm{q}_{\mathrm{i}}\right)$.

Misalkan $\mathrm{W}=\bigcup_{\mathrm{i}=1}^{\mathrm{n}} \mathrm{W}_{\mathrm{ri}}\left(\mathrm{q}_{\mathrm{i}}\right)$ dan $\mathrm{V}=\bigcap_{\mathrm{i}=1}^{\mathrm{n}} \mathrm{V}_{\mathrm{ri}}(\mathrm{p})$ maka $\mathrm{W} \cap \mathrm{V}=\phi$ dengan $\mathrm{W}$ dan $\mathrm{V}$ terbuka. Akibatnya $\mathrm{K} \cap \mathrm{V}=\phi$ dan berarti $\mathrm{V} \subset \mathrm{K}^{\mathrm{c}}$. Dengan kata lain terdapat himpunan terbuka $\mathrm{V}$ yang memuat $\mathrm{p}$ dengan sifat $\mathrm{V} \subset \mathrm{K}^{\mathrm{c}}$. Hal ini berarti $\mathrm{p}$ titik interior $\mathrm{K}^{\mathrm{c}}$. Karena $\mathrm{p} \in \mathrm{K}^{\mathrm{c}}$ sebarang maka $\mathrm{K}^{\mathrm{c}}$ terbuka. Jadi $\mathrm{K}$ tertutup.

\section{Teorema 5}

Himpunan bagian tertutup dari himpunan kompak adalah kompak. Artinya jika K kompak, $\mathrm{B} \subset \mathrm{K}$ dan $\mathrm{B}$ tertutup maka B kompak.

Bukti:

Diambil sebarang selimut terbuka $\left\{G_{\alpha}\right\}$ untuk B. Karena B tertutup maka B terbuka. Akibatnya $\left\{G_{\alpha}\right\} \cup B^{c}$ merupakan selimut terbuka untuk K. Karena $\mathrm{K}$ kompak maka ada $\alpha_{1}, \alpha_{2}, \cdots, \alpha_{n}$ sehingga $K \subset\left(\bigcup_{i=1}^{n} G_{\alpha i} \cup B^{c}\right)$. Dilain pihak $\mathrm{B} \subset \mathrm{K}$ maka diperoleh $\mathrm{B} \subset \bigcup_{\mathrm{i}=1}^{\mathrm{n}} \mathrm{G}_{\alpha \mathrm{i}}$. Hal ini berarti B kompak.

\section{Akibat 6}

Jika $\mathrm{F}$ himpunan tertutup dan $\mathrm{K}$ kompak maka $\mathrm{F} \cap \mathrm{K}$ kompak. 
Bukti:

Karena K kompak maka berdasarkan teorema 4, K tertutup. Dilain pihak F tertutup maka $\mathrm{F} \cap \mathrm{K}$ tertutup. Akibatnya $\mathrm{F} \cap \mathrm{K}$ himpunan bagian tertutup dari himpunan kompak $\mathrm{K}$ dan berdasarkan teorema 5, $\mathrm{F} \cap \mathrm{K}$ kompak.

\section{Teorema 7}

Jika $\left\{\mathrm{K}_{\alpha}\right\}$ keluarga himpunan kompak pada ruang metrik $(\mathrm{X}, \mathrm{d})$ sehingga setiap keluarga bagian berhingganya mempunyai irisan tak kosong maka $\bigcap_{\alpha} K_{\alpha} \neq \phi$.

Artinya jika $\mathrm{K}_{\alpha}$ himpunan kompak untuk setiap $\alpha$ dan $\bigcap_{\mathrm{i}=1}^{\mathrm{n}} \mathrm{K}_{\alpha \mathrm{i}} \neq \phi$ untuk setiap $\mathrm{n} \in \mathrm{N}$, maka $\bigcap_{\alpha} \mathrm{K}_{\alpha} \neq \phi$

Bukti:

Diambil satu anggota keluarga tertentu sebarang misalnya $K_{\alpha_{0}}$. Karena $K_{\alpha}$ kompak untuk setiap $\alpha$ maka $K_{\alpha}$ tertutup untuk setiap $\alpha$. Misalkan $K_{\alpha}^{c}=G_{\alpha}$ maka $G_{\alpha}$ terbuka untuk setiap $\alpha$. Akan diperlihatkan $\mathrm{K}_{\alpha_{0}} \cap\left(\bigcap_{\alpha \neq \alpha_{0}} \mathrm{~K}_{\alpha}\right) \neq \phi$.

Andaikan $\mathrm{K}_{\alpha_{0}} \cap\left(\bigcap_{\alpha \neq \alpha_{0}} \mathrm{~K}_{\alpha}\right)=\phi \quad$ maka $\mathrm{K}_{\alpha_{0}} \subset\left(\bigcap_{\alpha \neq \alpha_{0}} \mathrm{~K}_{\alpha}\right)^{\mathrm{c}}=\bigcup_{\alpha \neq \alpha_{0}} \mathrm{~K}_{\alpha}^{\mathrm{c}}=\bigcup_{\alpha \neq \alpha_{0}} \mathrm{G}_{\alpha}$. Berarti $\left\{\mathrm{G}_{\alpha}\right\}_{\alpha \neq \alpha_{0}}$ merupakan selimut terbuka untuk $\mathrm{K}_{\alpha_{0}}$. Karena $\mathrm{K}_{\alpha_{0}}$ kompak maka ada $\alpha_{1}, \alpha_{2}, \cdots, \alpha_{n}$ sehingga $K_{\alpha_{0}} \subset \bigcup_{i=1}^{n} G_{\alpha i}=\bigcup_{i=1}^{n} K_{\alpha i}^{c}=\left(\bigcap_{i=1}^{n} K_{\alpha i}\right)^{c}$. Dengan kata lain $\mathrm{K}_{\alpha_{0}} \cap\left(\bigcap_{\mathrm{i}=1}^{\mathrm{n}} \mathrm{K}_{\alpha_{\mathrm{i}}}\right)=\phi$ atau $\mathrm{K}_{\alpha_{0}} \cap \mathrm{K}_{\alpha_{1}} \cap \mathrm{K}_{\alpha_{2}} \cap \cdots \cap \mathrm{K}_{\alpha_{\mathrm{n}}}=\phi$. Hal ini kontradiksi dengan yang diketahui bahwa setiap keluarga bagian berhingga mempunyai irisan tak kosong. Dengan demikian pengandaian salah dan haruslah $\mathrm{K}_{\alpha_{0}} \cap\left(\bigcap_{\alpha \neq \alpha_{0}} \mathrm{~K}_{\alpha}\right) \neq \phi$ untuk setiap $\alpha$. Karena $\mathrm{K}_{\alpha_{0}}$ sebarang maka $\bigcap_{\alpha} \mathrm{K}_{\alpha} \neq \phi$. 


\section{Akibat 8}

Jika $\left\{\mathrm{K}_{\mathrm{n}}\right\}_{\mathrm{n} \geq 1}$ keluarga himpunan kompak yang tak kosong dengan $\mathrm{K}_{\mathrm{n}} \supset \mathrm{K}_{\mathrm{n}+1}$ untuk setiap $\mathrm{n} \in \mathrm{N}$ maka $\bigcap_{\mathrm{n}=1}^{\infty} \mathrm{K}_{\mathrm{n}} \neq \phi$.

Bukti:

Diketahui $K_{n}$ himpunan kompak untuk setiap n. Karena $K_{n} \supset K_{n+1}$ untuk setiap $\mathrm{n} \in \mathrm{N}$ maka $\bigcap_{\mathrm{n}=1}^{\mathrm{m}} \mathrm{K}_{\mathrm{n}}=\mathrm{K}_{\mathrm{m}}$ dan berarti $\bigcap_{\mathrm{n}=1}^{\mathrm{m}} \mathrm{K}_{\mathrm{n}} \neq \phi$. Berdasarkan teorema 7 maka $\bigcap_{n=1}^{\infty} K_{n} \neq \phi$

\section{Teorema 9}

Jika $\mathrm{E}$ himpunan bagian tak berhingga dalam himpunan kompak $\mathrm{K}$ maka $\mathrm{E}$ mempunyai titik limit di $\mathrm{K}$.

Bukti:

Andaikan E tidak mempunyai titik limit di $\mathrm{K}$. Jadi jika $\mathrm{p} \in \mathrm{K}$ maka $\mathrm{p}$ bukan titik limit dari $\mathrm{E}$ atau ada persekitaran $\mathrm{N}_{\mathrm{r}}(\mathrm{p})$ sehingga $\mathrm{N}_{\mathrm{r}}(\mathrm{p}) \backslash\{\mathrm{p}\} \cap \mathrm{E}=\phi$. Dengan demikian setiap $\mathrm{N}_{\mathrm{r}}(\mathrm{p})$ tadi hanya memuat paling banyak satu titik anggota $\mathrm{E}$ yaitu titik $\mathrm{p}$ sendiri.

Jadi $\left\{\mathrm{N}_{\mathrm{r}}(\mathrm{p})\right\}_{\mathrm{p} \in \mathrm{K}}$ merupakan selimut terbuka untuk $\mathrm{K}$ dan juga merupakan selimut terbuka untuk $\mathrm{E}$ sebab $\mathrm{E} \subset \mathrm{K}$. Karena $\mathrm{K}$ kompak maka terdapat $\mathrm{p}_{1}, \mathrm{p}_{2}, \cdots, \mathrm{p}_{\mathrm{n}}$ sehingga $\mathrm{K} \subset \bigcup_{\mathrm{i}=1}^{\mathrm{n}} \mathrm{N}_{\mathrm{r}}\left(\mathrm{p}_{\mathrm{i}}\right)$ dan juga $\mathrm{E} \subset \bigcup_{\mathrm{i}=1}^{\mathrm{n}} \mathrm{N}_{\mathrm{r}}\left(\mathrm{p}_{\mathrm{i}}\right)$. Padahal setiap $\mathrm{N}_{\mathrm{r}}\left(\mathrm{p}_{\mathrm{i}}\right)$ hanya memuat paling banyak satu anggota $\mathrm{E}$ dan ini berarti anggota $\mathrm{E}$ berhingga. Hal ini kontradiksi dengan yang diketahui bahwa E tak berhingga. Dengan demikian pengandaian salah dan haruslah E mempunyai titik limit di K.

\section{Teorema 10}

Jika $\left\{I_{n}\right\}$ barisan interval tertutup dan terbatas di $R$ sehingga $I_{n} \supset I_{n+1}$ untuk setiap $\mathrm{n} \in \mathrm{N}$ maka $\bigcap_{\mathrm{n}=1}^{\infty} \mathrm{I}_{\mathrm{n}} \neq \phi$. 
Bukti:

Misalkan $I_{n}=\left[a_{n}, b_{n}\right]$. Karena $I_{n} \supset I_{n+1}$ untuk setiap $n \in N$ maka $a_{1} \leq a_{2} \leq \cdots \leq b_{1}$. Dengan kata lain $\left\{a_{n}: n \in N\right\}$ terbatas ke atas oleh $b_{1}$ dan berakibat $\left\{a_{n}: n \in N\right\}$ mempunyai suprimum katakan $\xi=\sup \left\{a_{n}: n \in N\right\}$.

Jadi $\mathrm{a}_{\mathrm{n}} \leq \xi$ untuk setiap $\mathrm{n} \in \mathbb{N}$.

Selanjutnya akan ditunjukkan $\xi \leq \mathrm{b}_{\mathrm{n}}$ untuk setiap $\mathrm{n} \in \mathrm{N}$. Diambil sebarang $\mathrm{n}_{0} \in \mathrm{N}$. Jika $\mathrm{n}<\mathrm{n}_{0}$ maka $\mathrm{a}_{\mathrm{n}} \leq \mathrm{a}_{\mathrm{n}_{0}} \leq \mathrm{b}_{\mathrm{n}_{0}}$ dan jika $\mathrm{n} \geq \mathrm{n}_{0}$ maka $\mathrm{a}_{\mathrm{n}} \leq \mathrm{b}_{\mathrm{n}} \leq \mathrm{b}_{\mathrm{n}_{0}}$. Jadi $\mathrm{b}_{\mathrm{n}_{0}}$ batas atas $\left\{\mathrm{a}_{\mathrm{n}}: \mathrm{n} \in \mathrm{N}\right\}$. Akibatnya $\xi \leq \mathrm{b}_{\mathrm{n}_{0}}$ dan karena $\mathrm{n}_{0} \in \mathrm{N}$ sebarang maka $\xi \leq \mathrm{b}_{\mathrm{n}}$ untuk setiap $\mathrm{n} \in \mathbb{N}$.

Dari persamaan (1) dan (2) diperoleh $a_{n} \leq \xi \leq b_{n}$ untuk setiap $n \in \mathbb{N}$ atau $\xi \in \bigcap_{n=1}^{\infty}\left[a_{n}, b_{n}\right]=\bigcap_{n=1}^{\infty} I_{n}$ atau $\bigcap_{n=1}^{\infty} I_{n} \neq \phi$.

\section{Teorema 11}

Jika $\left\{\mathrm{I}_{\mathrm{n}}\right\}$ barisan sel-k tertutup dan terbatas di $\mathrm{R}^{\mathrm{k}}$ dengan $\mathrm{k}$ bilangan bulat positif sehingga $I_{n} \supset I_{n+1}$ untuk setiap $n \in N$ maka $\bigcap_{n=1}^{\infty} I_{n} \neq \phi$.

Bukti:

Misalkan $\mathrm{I}_{\mathrm{n}}=\left\{\overline{\mathrm{x}}: \overline{\mathrm{x}}=\left(\mathrm{x}_{1}, \mathrm{x}_{2}, \cdots, \mathrm{x}_{\mathrm{k}}\right), \mathrm{a}_{\mathrm{nj}} \leq \mathrm{x}_{\mathrm{j}} \leq \mathrm{b}_{\mathrm{nj}}, 1 \leq \mathrm{j} \leq \mathrm{k}, \mathrm{n} \geq 1\right\}$.

Diambil $I_{n j}=\left[a_{n j}, b_{n j}\right]$ maka $I_{n j}$ tertutup dan terbatas untuk setiap $n, j \in \mathbb{N}$. Karena $\mathrm{I}_{\mathrm{n}} \supset \mathrm{I}_{\mathrm{n}+1}$ untuk setiap $\mathrm{n} \in \mathbb{N}$ maka $\mathrm{I}_{\mathrm{nj}} \supset \mathrm{I}_{(\mathrm{n}+1) \mathrm{j}}$ untuk setiap $\mathrm{j} \in \mathbb{N}$. Jadi $\left\{\mathrm{I}_{\mathrm{nj}}\right\}$ merupakan interval bersarang, tertutup dan terbatas, dan berdasarkan teorema 10 terdapat $\mathrm{x}_{\mathrm{j}}^{*}$ sehingga $\mathrm{a}_{\mathrm{nj}} \leq \mathrm{x}_{\mathrm{j}}^{*} \leq \mathrm{b}_{\mathrm{nj}}$ untuk setiap $1 \leq \mathrm{j} \leq \mathrm{k}, \mathrm{n} \geq 1$. Kemudian dibentuk $\overline{\mathrm{x}}^{*}=\left(\mathrm{x}_{1}^{*}, \mathrm{x}_{2}^{*}, \cdots, \mathrm{x}_{\mathrm{k}}^{*}\right)$ maka $\overline{\mathrm{x}}^{*} \in \mathrm{I}_{\mathrm{n}}$ untuk setiap $\mathrm{n} \in \mathbb{N}$. Dengan $\operatorname{demikian} \bigcap_{\mathrm{n}=1}^{\infty} \mathrm{I}_{\mathrm{n}} \neq \phi$

\section{Teorema 12}

Setiap sel-k selalu kompak.

Bukti:

Diambil sebarang sel-k misalnya I yang memuat titik-titik $\bar{x}=\left(x_{1}, x_{2}, \cdots, x_{k}\right)$ sehingga $\mathrm{a}_{\mathrm{j}} \leq \mathrm{x}_{\mathrm{j}} \leq \mathrm{b}_{\mathrm{j}}, 1 \leq \mathrm{j} \leq \mathrm{k}$. Misal $\delta$ adalah panjang diagonal dari sel $\mathrm{I}$ 
tersebut yaitu $\delta=\left[\sum_{\mathrm{j}=1}^{\mathrm{k}}\left(\mathrm{b}_{\mathrm{j}}-\mathrm{a}_{\mathrm{j}}\right)^{2}\right]^{\frac{1}{2}} . \quad$ Jadi untuk setiap $\overline{\mathrm{x}}, \overline{\mathrm{y}} \in \mathrm{I}$ berlaku $|\overline{\mathrm{x}}-\overline{\mathrm{y}}|<\delta$. Andaikan I tidak kompak maka ada selimut terbuka $\left\{\mathrm{G}_{\alpha}\right\}$ untuk I yang tidak memuat selimut bagian berhingganya untuk I. Diambil $\mathrm{c}_{\mathrm{j}}=\frac{\mathrm{a}_{\mathrm{j}}+\mathrm{b}_{\mathrm{j}}}{2}, 1 \leq \mathrm{j} \leq \mathrm{k}$ maka interval-interval $\left[\mathrm{a}_{\mathrm{j}}, \mathrm{c}_{\mathrm{j}}\right]$ dan $\left[\mathrm{c}_{\mathrm{j}}, \mathrm{b}_{\mathrm{j}}\right]$ membagi sel $\mathrm{I}$ menjadi $2^{\mathrm{k}}$ bagian dan namakan setiap bagiannya itu dengan $\mathrm{Q}_{\mathrm{i}}, 1 \leq \mathrm{i} \leq 2^{\mathrm{k}}$. Maka paling sedikit ada satu $\mathrm{Q}_{i}$ yang tidak diselimuti oleh keluarga bagian berhingga $\left\{\mathrm{G}_{\alpha}\right\}$ dan sebut $\mathrm{Q}_{i}$ yang tidak diselimuti tadi oleh $\mathrm{I}_{1}$. Kemudian $\mathrm{I}_{1}$ dibagi lagi dengan mengambil $\mathrm{d}_{\mathrm{j}}=\frac{\mathrm{a}_{\mathrm{j}}+\mathrm{c}_{\mathrm{j}}}{2}, 1 \leq \mathrm{j} \leq \mathrm{k}$, maka diantaranya ada yang tidak diselimuti oleh $\left\{\mathrm{G}_{\alpha}\right\}$ dan namakan $\mathrm{I}_{2}$. Jika proses diteruskan maka diperoleh

(a) $\mathrm{I} \supset \mathrm{I}_{1} \supset \mathrm{I}_{2} \supset \cdots$

(b) $\mathrm{I}_{\mathrm{n}}$ tidak dapat diselimuti oleh setiap keluarga bagian berhingga $\left\{\mathrm{G}_{\alpha}\right\}$

(c) Jika $\bar{x}, \bar{y} \in I_{n}$ maka $|\bar{x}-\bar{y}|<2^{-n} \delta$ untuk setiap $n \in \mathbb{N}$ sebab, jika $\bar{x}, \bar{y} \in I$ berlaku $|\bar{x}-\bar{y}|<\delta$

jika $\overline{\mathrm{x}}, \overline{\mathrm{y}} \in \mathrm{I}_{1}$ berlaku $|\overline{\mathrm{x}}-\overline{\mathrm{y}}|<2^{-1} \delta$ (diagonal $\mathrm{I}_{1}=\frac{1}{2}$ diagonal I)

jika $\overline{\mathrm{x}}, \overline{\mathrm{y}} \in \mathrm{I}_{2}$ berlaku $|\overline{\mathrm{x}}-\overline{\mathrm{y}}|<2^{-2} \delta$ (diagonal $\mathrm{I}_{2}=\frac{1}{2}$ diagonal $\mathrm{I}_{1}$ )

jika $\bar{x}, \bar{y} \in I_{n}$ berlaku $|\bar{x}-\bar{y}|<2^{-n} \delta\left(\right.$ diagonal $I_{n}=\frac{1}{2}$ diagonal $\left.I_{n-1}\right)$

Dari (a) dan berdasarkan teorema 11 maka terdapat $\overline{\mathrm{x}}^{*} \in \mathrm{I}_{\mathrm{n}}$ untuk setiap $\mathrm{n} \in \mathrm{N}$ dan karena $\left\{\mathrm{G}_{\alpha}\right\}$ selimut terbuka untuk I maka $\overline{\mathrm{x}}^{*} \in \mathrm{G}_{\alpha}$ untuk suatu $\alpha$. Karena $\mathrm{G}_{\alpha}$ himpunan terbuka maka $\overline{\mathrm{x}}^{*}$ merupakan titik interior $\mathrm{G}_{\alpha}$ artinya terdapat bilangan $\mathrm{r}>0$ sehingga $\left|\overline{\mathrm{x}}^{*}-\overline{\mathrm{y}}\right|<\mathrm{r}$ untuk setiap $\overline{\mathrm{y}} \in \mathrm{G}_{\alpha}$. Diambil $\mathrm{n}$ yang cukup besar sehingga $2^{-\mathrm{n}} \delta<\mathrm{r}$ maka berdasarkan [c] diperoleh $|\overline{\mathrm{x}}-\overline{\mathrm{y}}|<\mathrm{r}$ untuk setiap $\overline{\mathrm{x}}, \overline{\mathrm{y}} \in \mathrm{I}_{\mathrm{n}}$. Dengan kata lain $\mathrm{I}_{\mathrm{n}} \subset \mathrm{G}_{\alpha}$ untuk setiap $\mathrm{n} \in \mathrm{N}$ dan hal ini kontradiksi dengan (b). Jadi pengandaian salah dan haruslah I kompak.

\section{Teorema 13}

Jika $\mathrm{E} \subset \mathrm{R}^{\mathrm{k}}$ maka pernyataan berikut equivalen

(a) E tertutup dan terbatas 
(b) E kompak

(c) Setiap himpunan bagian tak berhingga pada E mempunyai titik limit di E.

Bukti:

(a) $\Rightarrow$ (b)

Karena E terbatas maka E termuat dalam suatu sel I yang kompak (teorema 12). Akibatnya E merupakan himpunan bagian tertutup dalam himpunan kompak I dan berdasarkan teorema 5 maka E kompak.

(b) $\Rightarrow$ (c)

Misal F himpunan bagian tak berhingga didalam E yang kompak maka berdasarkan teorema 9, F mempunyai titik limit di E.

(c) $\Rightarrow$ (a)

Diketahui setiap himpunan bagian tak berhingga dalam E mempunyai titik limit di E. Akan diperlihatkan E tertutup dan terbatas.

(i) $\mathrm{E}$ terbatas di $\mathrm{R}^{\mathrm{k}}$ jika terdapat $\mathrm{M} \in \mathrm{R}$ sehingga untuk setiap $\overline{\mathrm{x}} \in \mathrm{E}$ dan suatu $\overline{\mathrm{y}} \in \mathrm{R}^{\mathrm{k}}$ berlaku $|\overline{\mathrm{x}}-\overline{\mathrm{y}}| \leq \mathrm{M}$. Andaikan $\mathrm{E}$ tidak terbatas maka ada $\overline{\mathrm{x}}_{\mathrm{n}} \in \mathrm{E}$ sehingga $\overline{\mathrm{x}}_{\mathrm{n}}>\mathrm{n}$ untuk setiap $\mathrm{n} \in \mathrm{N}$ dan suatu $\overline{\mathrm{y}}_{\mathrm{n}}=\theta \in \mathrm{R}^{\mathrm{k}}$.

Dibentuk $\mathrm{S}=\left\{\overline{\mathrm{x}}_{\mathrm{n}}: \overline{\mathrm{x}}_{\mathrm{n}} \in \mathrm{E},\left|\overline{\mathrm{x}}_{\mathrm{n}}\right|>\mathrm{n}, \mathrm{n} \in \mathrm{N}\right\}$ maka $\mathrm{S} \subset \mathrm{E}, \mathrm{S}$ tak berhingga dan tidak mempunyai titik limit di E. Hal ini kontradiksi dengan yang diketahui bahwa setiap himpunan bagian tak berhingga dalam E mempunyai titik limit di E. Jadi pengandaian salah dan haruslah E terbatas.

(ii) Andaikan $\mathrm{E}$ tidak tertutup di $\mathrm{R}^{\mathrm{k}}$ maka ada $\overline{\mathrm{x}}_{0} \in \mathrm{R}^{\mathrm{k}}$ titik limit $\mathrm{E}$ dengan $\overline{\mathrm{x}}_{0} \notin \mathrm{E}$. Diambil $\mathrm{r}_{1}=1$ maka ada $\overline{\mathrm{x}}_{1} \in \mathrm{E}$ dengan $\left|\overline{\mathrm{x}}_{1}-\overline{\mathrm{x}}_{0}\right|<1$

$$
\begin{gathered}
\mathrm{r}_{2}=\frac{1}{2} \text { maka ada } \overline{\mathrm{x}}_{2} \in \mathrm{E} \text { dengan }\left|\overline{\mathrm{x}}_{2}-\overline{\mathrm{x}}_{0}\right|<\frac{1}{2} \\
\vdots \\
\mathrm{r}_{\mathrm{n}}=\frac{1}{\mathrm{n}} \text { maka ada } \overline{\mathrm{x}}_{\mathrm{n}} \in \mathrm{E} \text { dengan }\left|\overline{\mathrm{x}}_{\mathrm{n}}-\overline{\mathrm{x}}_{0}\right|<\frac{1}{\mathrm{n}}
\end{gathered}
$$

Dibentuk himpunan $\mathrm{S}=\left\{\overline{\mathrm{x}}_{\mathrm{n}}: \overline{\mathrm{x}}_{\mathrm{n}} \in \mathrm{E},\left|\overline{\mathrm{x}}_{\mathrm{n}}-\overline{\mathrm{x}}_{0}\right|<\frac{1}{\mathrm{n}}\right\}$ maka $\mathrm{S}$ himpunan bagian tak berhingga pada $E$ dan hanya mempunyai satu titik limit yaitu $\overline{\mathrm{x}}_{0}$ dengan $\overline{\mathrm{x}}_{0} \notin \mathrm{E}$. Jadi $\mathrm{S}$ himpunan bagian tak berhingga pada $\mathrm{E}$ dan tidak mempunyai 
titik limit di E. Hal ini kontradiksi dengan yang diketahui. Jadi pengandaian salah dan haruslah E tertutup.

\section{Teorema 14 (Teorema Heine-Borel)}

$\mathrm{E} \subset \mathrm{R}^{\mathrm{k}}$ kompak jika dan hanya jika E tertutup dan terbatas.

Bukti:

Syarat cukup $(\Leftarrow)$ sudah dibuktikan pada teorema 13 (a) $\Rightarrow$ (b)

Syarat perlu $(\Rightarrow)$

(i) Akan diperlihatkan E tertutup yaitu E mengandung seluruh titik limitnya. Misal $p$ sebarang titik limit $E$ maka untuk setiap persekitaran $\mathrm{N}_{\mathrm{r}}(\mathrm{p})$ berlaku $\mathrm{N}_{\mathrm{r}}(\mathrm{p}) \backslash\{\mathrm{p}\} \cap \mathrm{E} \neq \phi$. Akibatnya $\mathrm{N}_{\mathrm{r}}(\mathrm{p}) \cap \mathrm{E} \neq \phi$ untuk setiap bilangan $\mathrm{r}>0$. Jadi terdapat $\mathrm{q} \in \mathrm{E}$ dan $\mathrm{q} \in \mathrm{N}_{\mathrm{r}}(\mathrm{p})=\{\mathrm{x}:|\mathrm{x}-\mathrm{p}|<\mathrm{r}\}$ yang berakibat $|\mathrm{q}-\mathrm{p}|<\mathrm{r}$ untuk setiap $r>0$ atau $q=p \in E$. Karena $p$ sebarang titik limit dari E maka $E$ mengandung seluruh titik limitnya. Dengan kata lain E tertutup.

(ii) Akan ditunjukkan $\mathrm{E}$ terbatas yaitu setiap $\overline{\mathrm{x}} \in \mathrm{E}$ dan suatu $\overline{\mathrm{y}} \in \mathrm{R}^{\mathrm{k}}$ berlaku $|\overline{\mathrm{x}}-\overline{\mathrm{y}}|<\mathrm{M}$. Diambil $\overline{\mathrm{x}} \in \mathrm{E}$ sebarang dan kemudian dibentuk persekitaran $\mathrm{N}_{\mathrm{r}}(\overline{\mathrm{x}})=\left\{\overline{\mathrm{y}}: \overline{\mathrm{y}} \in \mathrm{R}^{\mathrm{k}},|\overline{\mathrm{x}}-\overline{\mathrm{y}}|<\mathrm{r}\right\}$ maka keluarga $\left\{\mathrm{N}_{\mathrm{r}}(\overline{\mathrm{x}})\right\}$ merupakan selimut terbuka untuk E. Karena E kompak maka terdapat $\overline{\mathrm{x}}_{1}, \overline{\mathrm{x}}_{2}, \cdots, \overline{\mathrm{x}}_{\mathrm{n}}$ sehingga $\mathrm{E} \subset \bigcup_{\mathrm{i}=1}^{\mathrm{n}} \mathrm{N}_{\mathrm{r}}\left(\overline{\mathrm{x}}_{\mathrm{i}}\right) . \quad$ Diambil $\mathrm{M}=\operatorname{maks}\left\{|\overline{\mathrm{x}}-\overline{\mathrm{y}}|: \overline{\mathrm{x}}, \overline{\mathrm{y}} \in \mathrm{N}_{\mathrm{r}}\left(\overline{\mathrm{x}}_{\mathrm{i}}\right), \mathrm{i}=1,2, \cdots, \mathrm{n}\right\}$ maka untuk setiap $\overline{\mathrm{x}} \in \mathrm{E}$ dan suatu $\overline{\mathrm{y}} \in \mathrm{R}^{\mathrm{k}}$ berlaku $|\overline{\mathrm{x}}-\overline{\mathrm{y}}|<\mathrm{M}$. Hal ini berarti E terbatas.

\section{Teorema 15 (Teorema Bolzano-Weierstrass)}

Setiap himpunan tak berhingga dan terbatas di $\mathrm{R}^{\mathrm{k}}$ mempunyai titik limit di $\mathrm{R}^{\mathrm{k}}$.

Bukti:

Misal E himpunan tak berhingga dan terbatas di $\mathrm{R}^{\mathrm{k}}$ maka $\mathrm{E}$ termuat dalam suatu sel I yang kompak dan berdasarkan teorema 9, maka E mempunyai titik limit pada I dengan $\mathrm{I} \subset \mathrm{R}^{\mathrm{k}}$. Jadi $\mathrm{E}$ mempunyai titik limit di $\mathrm{R}^{\mathrm{k}}$.

\section{Contoh}

(a) Jika $\mathrm{A}=(0,1] \subset \mathrm{R}$, apakah A kompak?

Jawab : 
A tidak kompak sebab ada selimut terbuka $\left\{\mathrm{G}_{\mathrm{n}}\right\}$ untuk A yang tidak memuat selimut bagian berhingganya untuk $A$, yaitu $G_{n}=\left(\frac{1}{n}, 1+\frac{1}{n}\right), n=1,2, \ldots$

Jelas $A \subset \bigcup_{n} G_{n}=(0,2)$ tetapi $A \not \subset \bigcup_{n=1}^{k} G_{n}$ sebab $\frac{1}{k} \in A, k=1,2, \ldots$, tetapi $\frac{1}{\mathrm{k}} \notin \bigcup_{\mathrm{n}=1}^{\mathrm{k}} \mathrm{G}_{\mathrm{n}}=\left(\frac{1}{\mathrm{k}}, 2\right)$.

(b) Apakah $\mathrm{F}=\left\{0,1, \frac{1}{2}, \frac{1}{3}, \cdots\right\}$ kompak?

Jawab :

Himpunan titik limit dari $\mathrm{F}$ adalah $\mathrm{F}^{\prime}=\{0\}$. Jadi $\mathrm{F}$ mengandung semua titik limitnya dan berarti $F$ tertutup. Dilain pihak $F$ juga terbatas oleh $[0,1]$ dan berdasarkan teorema 14 (teorema Heine Borel) maka F adalah kompak.

\section{Kesimpulan}

Dengan menggunakan definisi kompak kita dapat menentukan apakah suatu himpunan kompak atau tidak, tetapi cara yang lebih mudah adalah dengan menggunakan teorema Heine-Borel yaitu suatu himpunan E pada ruang metrik $(\mathrm{X}, \mathrm{d})$ adalah kompak jika dan hanya jika E tertutup dan terbatas. Dengan memeriksa ketertutupan dan keterbatasan suatu himpunan maka kita dapat menentukan kekompakan suatu himpunan.

\section{Daftar Pustaka}

Apostol, T.M. (1974). Mathematical Analysis (Second Edition). Addison-Wesley Publishing Company, Inc. Philippines.

Bartle, R.G. (1976). The Elements Of Real Analysis (Second Edition). John Wiley \& Sons, Inc. USA.

Munkres, J.R. (1975). Topologi (A First Course). Prentice-Hall, Inc, Englewood Cliffs, New Jersey. USA.

Rudin, W. (1976). Principles of Mathematical Analysis (Third Edition). McGraw-Hill. Singapore. 